\title{
Grain refining of a Ti-6Al-4V alloy by high-pressure torsion and low temperature superplasticity
}

\author{
J. Fu ${ }^{1,2}$, H. Ding ${ }^{1 \dagger}$, Y. Huang ${ }^{3}$, P. H. R.Pereira ${ }^{3}$, W.Zhang ${ }^{1}$, \\ T. G. Langdon ${ }^{3,4}$ \\ †hding@263.net \\ ${ }^{1}$ School of Materials and Metallurgy, Northeastern University, Shenyang 110819 China \\ ${ }^{2}$ Western Superconducting Technologies Co. Ltd,Xi'an 710018 China \\ ${ }^{3}$ Material Research Group, Faculty of Engineering \& Environment, University of Southampton, Southampton SO17 1BJ, U.K \\ ${ }^{4}$ Departments of Aerospace \&Mechanical Engineering and Material Science, University of Southern California, \\ Los Angeles, CA90089-1453, USA
}

\begin{abstract}
A cold-rolled Ti-6Al-4V sheet was subjected to heat treatmentprior to processing by high-pressure torsion (HPT). Quantitative measurements revealed that the volume fractions were $25 \%$ equiaxed $\alpha$ phase and $75 \%$ lamellar $(\alpha+\beta)$. The grain size of the $\alpha$ phase was $9.5 \pm 1.5 \mu \mathrm{m}$. The processing by HPT was performed at room temperature with a pressure of $6.0 \mathrm{GPa}$ and a rotation speed of $1 \mathrm{rpm}$. Processing of the material was conducted through a total number of revolutions, N, of $1 / 4,1,5,10$ and 20. After 1 turn in HPT, the traces of shear deformation appeared. When the turns increased to 5, shear deformation was more severe. After 10 turns, the fibrous structure basically disappeared and ultrafine equiaxed grains were formed. When the deformation proceeded to 20 turns, a series ofhigh-angle boundaries were formed in the sample and the average size of equiaxed grains was $77 \pm 15 \mathrm{~nm}$.After HPT processing, the microhardness increased as the numbers of HPT turns increased and the distribution of hardness tended to be relatively homogeneous when the HPT continued to 20 turns.Superplastic deformation tests were performed at $873 \mathrm{~K}$ at different strain rates in the material processed by HPT and an elongation of $790 \%$ was achieved when deforming at $873 \mathrm{~K}$ and $10^{-4} \mathrm{~s}^{-1}$.
\end{abstract}

Keywords: grain refinement, high-pressure torsion, microhardness, superplasticity, Ti-6Al-4V alloy

\section{Измельчение зерен в сплаве Ti-6Al-4V кручением под высоким давлением и низкотемпературная сверхпластичность}

Лист прокатанного сплава Ti-6Al-4V был подвергнут термической обработке перед деформацией кручением под высоким давлением (КВД). Количественные измерения показали, что материал содержит $25 \%$ объемной доли а фазы и 75\% пластинчатой $(\alpha+\beta)$ фазы. Размер зерен а фазы был равен $9.5 \pm 1.5$ мкм. Деформация путем КВД была осуществлена при комнатной температуре под давлением 6.0 ГПа при скорости вращения 1 об/мин. Деформация материала производилась до полного числа оборотов $\mathrm{N}$, равного $1 / 4,1,5,10$ и 20. После одного оборота КВД появляются следы деформации сдвигом. Когда число оборотов достигает 5, деформация сдвигом становится более выраженной. После 10 оборотов волокнистая структура практически исчезает, и формируются ультрамелкие равноосные зерна. Когда деформация продолжается до 20 оборотов, в образце образуется множество высокоугловых границ зерен, и средний размер равноосных зерен равен $77 \pm 15$ нм. После деформации КВД микротвердость растет с увеличением числа оборотов и имеет тенденцию относительно равномерного распределения, когда КВД продолжается до 20 оборотов. Были проведены испытания на сверхпластическую деформацию материала после КВД при температуре $873 \mathrm{~K}$ при различных скоростях деформации, и достигнуто относительное удлинение $790 \%$ при деформации при $873 \mathrm{~K}$ и $10^{-4} \mathrm{c}^{-1}$.

Ключевые слова: измельчение зерен, кручение под высоким давлением, микротвердость, сверхпластичность, сплав Ti-6Al-4V 


\section{Introduction}

Titanium alloys have been extensively utilized in the aerospace and automobile industries as they possess high strength, high toughness and good corrosion resistance. They are also good bio-materials due to their excellent biocompatibility.

Superplastic deformation is an effective way to process materials with high deformation resistance such as Ti alloys and grain refining can result in a decrease in deformation temperature which is beneficial to the energy savings and the reduction of tool costs. Generally, the superplastic deformation temperature of Ti-6Al-4V alloys is relatively high $(\sim 1173 \mathrm{~K})$ so that many techniques have been adopted to refine the grain size of the alloy in order to decrease the superplastic temperature of the material. When thermomechanical processing was utilized, the grain size was reduced to about $3 \mu \mathrm{m}$ and the alloy was able to achieve good superplasticity at $1073 \mathrm{~K}$ [1].

In practice, severe plastic deformation (SPD) techniques are very efficient in refining the grain sizes of materials. They have been used to refine the microstructures of Ti-6Al-4V alloys and the superplastic behavior of ultrafine grained materials has been investigated [2-6]. It was demonstrated that the elongation was increased significantly with an increase in the equal channel angular pressing (ECAP) straining from 4 to 8 and this was associated with a higher proportion of high-angle boundaries and a lower activation energy $[2,3]$. An elongation of $530 \%$ was achieved at $923 \mathrm{~K}$ and $10^{-4} \mathrm{~s}^{-1}$. Superplastic behavior of the ultrafinegrained $\mathrm{Ti}-6 \mathrm{Al}-4 \mathrm{~V}$ alloy produced by high pressure torsion (HPT) has been investigated and a relatively high elongation $(>500 \%)$ was observed during tensile testing at $923 \mathrm{~K}$ and in the strain rate range from $10^{-3}$ to $10^{-4} \mathrm{~s}^{-1}[4,5]$. It was also reported that the superplasticity of nanocrystalline Ti- $6 \mathrm{Al}-4 \mathrm{~V}$ alloy was improved above $873 \mathrm{~K}$ after torsional straining [6].

Recently, there was a report of an investigation into the ultrafine-grained microstructure of the Ti-6Al-4V alloy produced by a hot working process by deforming an $\alpha^{\prime}$-martensite microstructure and low temperature and high strain rate superplastic behavior of the material was attained [7,8]. An elongation of $550 \%$ was reported at $973 \mathrm{~K}$ and $10^{-4} \mathrm{~s}^{-1}$ and it was stated that $\beta$-phase precipitation, which was accelerated during the deformation, acted as an accommodation mechanism and contributed to the enhancement of superplasticity of the material.

The influence of the phase volume fractions on the processing of a Ti-6Al-4V alloy by HPT were investigated $[9,10]$ and it was demonstrated that the grain size decreased with increasing numbers of turns in HPT processing and grain refinement may be optimized by processing an alloy with an approximately equal volume fraction of the two constituent phases. In earlier research, three different heat treatment schedules were adopted to attain different fractions of lamellar structure and it was demonstrated that the reduction in grain size was more severe when the fraction of lamellar structure increased [11].

Although some work has been conducted on the grain refining of ultrafine Ti-6Al-4V alloys, reports on the microstructural evolution during SPD in the initial material with a high proportion of lamellar structure and the superplastic behavior of the material are limited. In the present study, the grain refining process was investigated using HPT in the Ti-6Al-4V alloy containing about $75 \%$ lamellar structure. Microstructural evolution of the material during HPT was observed and the variation of microhardness was also measured. The occurrence of low temperature superplasticity was investigated to evaluate the potential of a material processed by HPT in further reducing the superplastic temperatures of the alloy.

\section{Experimental material and procedures}

A commercial cold-rolled Ti-6Al-4V sheet with a thickness of $2.3 \mathrm{~mm}$ was used. Prior to processing by HPT, a heat treatment was conducted at temperatures of $1243 \mathrm{~K} / 45 \mathrm{~min}+823 \mathrm{~K} / 3 \mathrm{~h}$. The processing by HPT was performed at room temperature using a conventional HPT facility [12]. The processing involved quasi-constrained conditions in which there is a small outflow of material around the periphery during the straining operation $[13,14]$. A pressure of $6.0 \mathrm{GPa}$ was applied to the disk and the lower anvil was rotated with a speed of $1 \mathrm{rpm}$. Processing of the material was conducted through total numbers of revolutions, $\mathrm{N}$, of $1 / 4,1,5,10$ and 20 .

Disks of $3 \mathrm{~mm}$ diameter were punched from the HPT samples at positions $3 \mathrm{~mm}$ from the center for transmission electron microscopy (TEM) as illustrated in Fig. 1. The TEM samples were ground mechanically to a thickness of about $50 \mu \mathrm{m}$. The foils for TEM were produced by twin-jet chemical polishing at a temperature of $243 \mathrm{~K}$ in a solution of $5 \%$ perchloric, $35 \%$ butanol and $60 \%$ methanol. Microstructural observations were performed using a Tecnai G220 TEM and the Vickers microhardness, Hv, was measured on the disks along the radial directions using an FM-700 microhardness tester under a load of $0.5 \mathrm{~kg}$ and with a dwell time of $15 \mathrm{~s}$. The procedure is also illustrated in Fig. 1. Miniature tensile specimens were cut from the samples and superplastic deformation testing was carried out using a Zwick 30KN Proline testing machine operating at a constant rate of cross-head displacement.

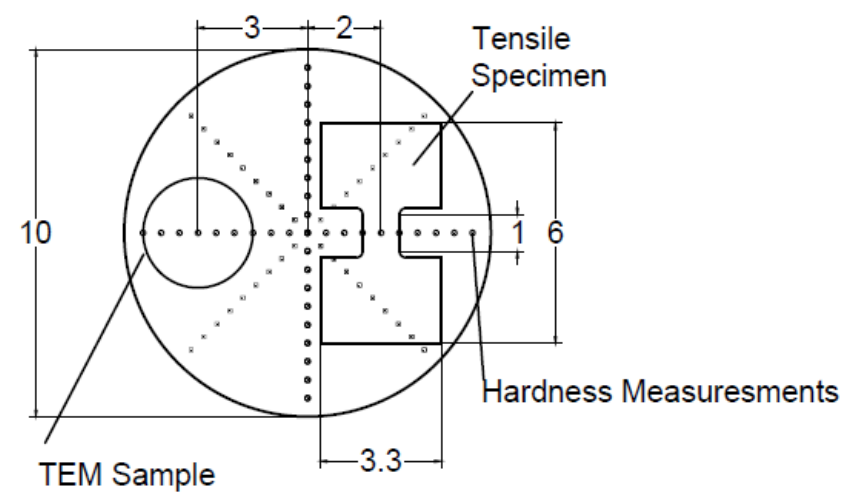

Fig. 1. Schematic illustration of the HPT sample showing the location of the TEM sample and tensile testing specimens and procedures for microhardness measurements. 


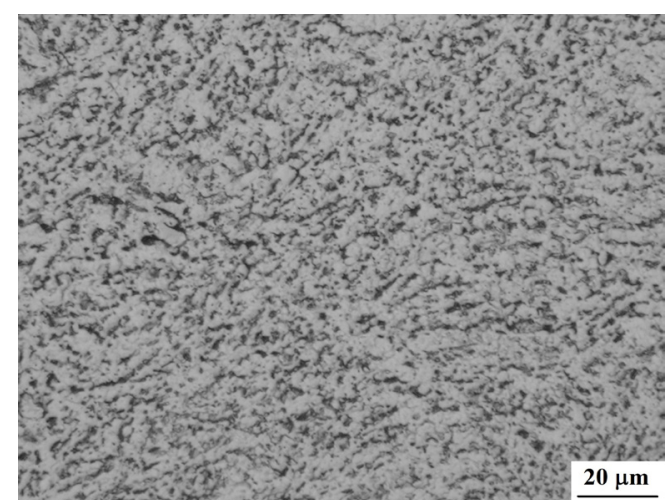

a

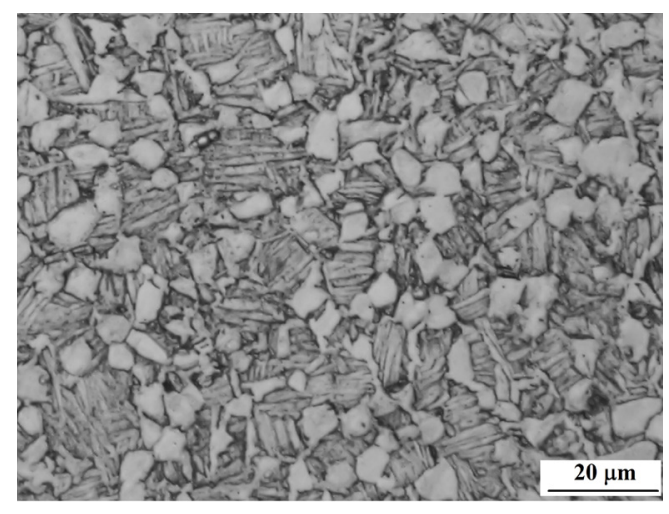

b

Fig. 2. Microstructures of the alloy: (a) as-received and (b) after heat treatments for $1243 \mathrm{~K} / 45 \mathrm{~min}+823 \mathrm{~K} / 3 \mathrm{~h}$.

\section{Experimental results}

\subsection{Effect of heat treatment on the microstructures of the Ti-6Al-4V alloy}

The microstructures of the as-received material and the material after the annealing treatment are shown in Fig. 2. It can be seen that the matrix is a phase and a small amount of $\beta$ phase exists in the as-received material (Fig. 2a). After the heat treatment, quantitative assessment revealed that the fraction of a phase in the alloy was about $25 \%$ and the grain size of the $\alpha$ phase was $9.5 \pm 1.5 \mu \mathrm{m}$ (Fig. 2b). The appearance of lamellar structure is because the annealing temperature approached the $\beta$ transformation temperature and part of the $\alpha$ phase transformed to $\beta$ phase when heated and a secondary a phase formed during cooling.

\subsection{Microstructural evolution during HPT processes}

Figure 3 presents representative microstructures of the alloy at different turns during HPT examined by TEM. In the primary stage, deformation was not very homogeneous. After 1 turn, traces of shear deformation appear and the SAED pattern exhibits individual spots indicating that the orientation angles among these traces are quite small (Fig. 3a). When the numbers of turns increases to 5 (Fig. 3b), it can be seen that the shear deformation is more severe, showing an increased dislocation density and finer curved fibrous $\alpha$ and $\beta$ phases are observed. The diffraction pattern is nearly ring-like and this indicates the grain

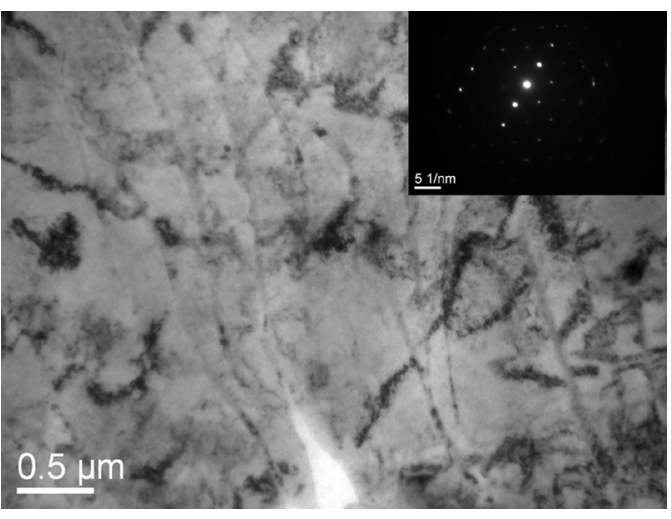

a

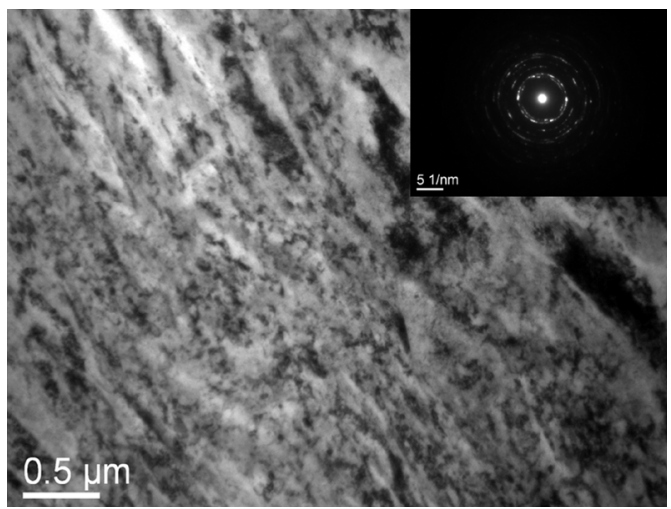

$\mathrm{b}$

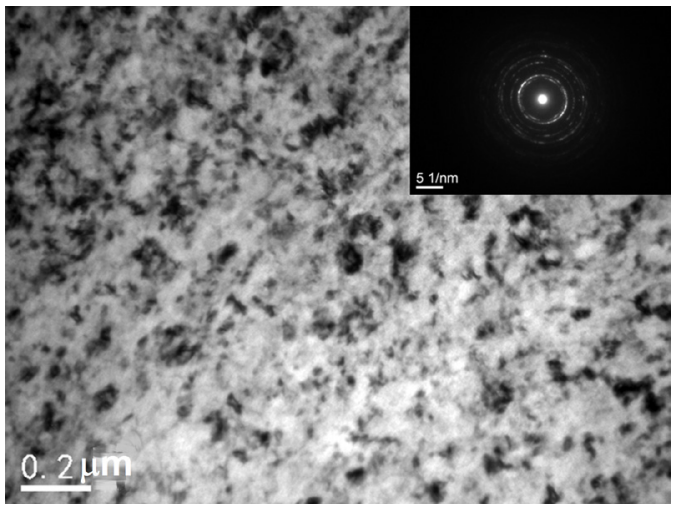

$\mathrm{C}$

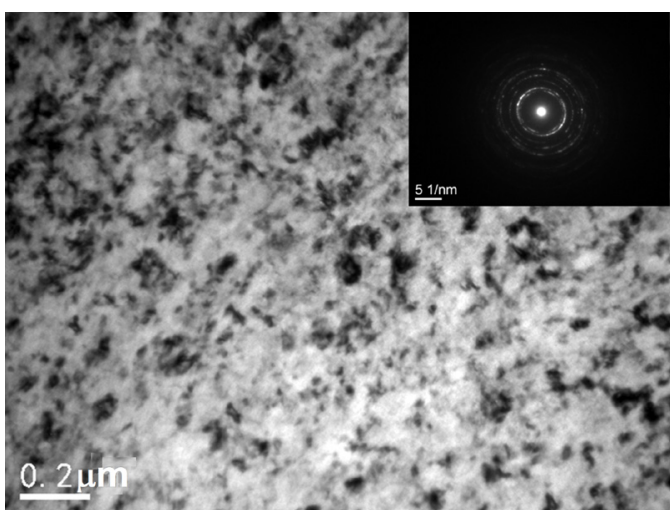

d

Fig. 3. TEM micrographs after processing by HPT for different turns (a) 1 turn; (b) 5 turns; (c) 10 turns; (d) 20 turns.

misorientations have increased as the process proceeds. After 10 turns, the fibrous structure has essentially disappeared and ultrafine equiaxed grains are formed (Fig. 3c). The average grain size was about $80 \pm 20 \mathrm{~nm}$ and the diffraction patterns 
are now more diffuse, thereby indicating that high-angle boundaries have formed. When the deformation proceeds to 20 turns, the Debye rings appear which means that more high-angle boundaries are formed in the sample (Fig. 3d). The average size of these equiaxed grains was $77 \pm 15 \mathrm{~nm}$. It appears that the extent of grain refining has saturated at this stage, and this is also suggested by the microhardness measurements described in the following section.

\subsection{Microhardness measurements}

Figure 4 shows plots of the average microhardness values against the distance from the center of the disk for the heattreated material and after processing by HPT. The microhardness value, $\mathrm{Hv}$, of the investigated alloy prior to HPT processing was about 349 . After HPT for $1 / 4$ turn, the microhardness increased and the average value reached 375 , but the microhardness distribution was not homogeneous along the radial direction and ranged from 390 at the periphery to 360 in the center. After 1 turn, the microhardness increased further to 410 at the edge but it remains relatively low in the center at $\sim 364$. There was an obvious increase in microhardness with increasing turns from 1 to 5 . After 5 turns, the values at the edges of the disk are very close to the saturation value whereas the hardness values in the center of the disk increase significantly. After 10 turns, the microhardness at the edges almost remains unchanged but it continues to increase in the center. The average microhardness reaches 435 after 20 turns and is essentially homogeneous except for a small area in the center. It is noticed that the central region with a lower hardness decreases with increasing turns in the HPT processing and the microhardness distribution is essentially homogeneous except for a central diameter of about $1 \mathrm{~mm}$.

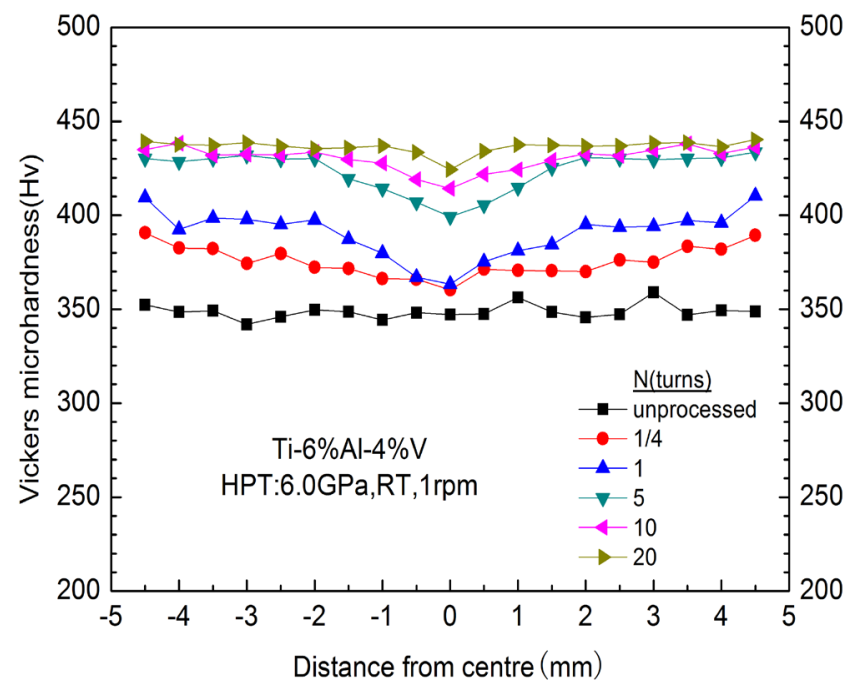

Fig. 4. Values of the Vickers microhardness plotted against the positions on the disks.

\subsection{Superplastic behavior}

Figure 5 shows the stress-strain curves of the Ti-6Al-4V samples deformed at a temperature of $873 \mathrm{~K}$ at different strain rates. It can be seen that typical superplastic flow, showing a

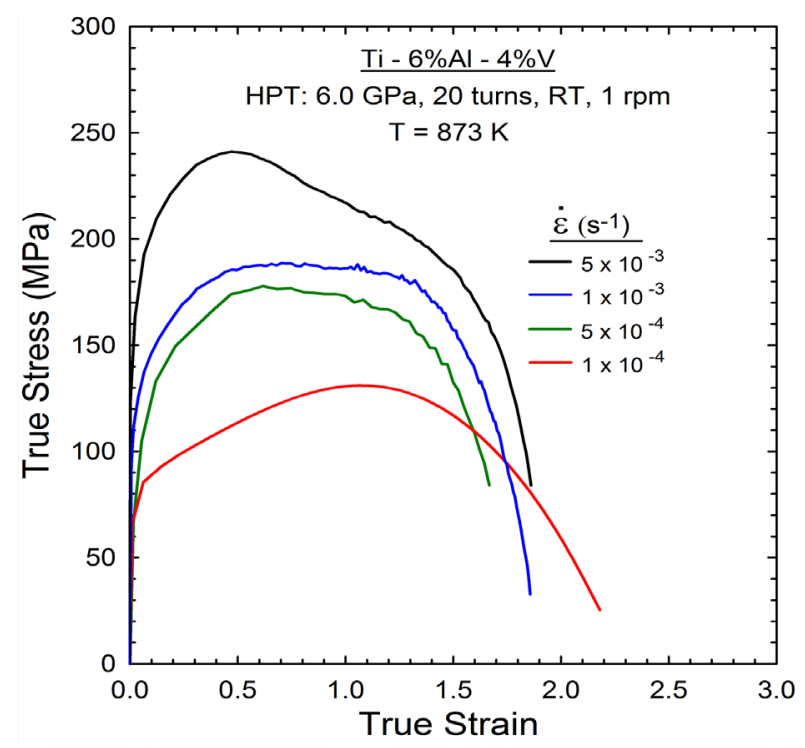

Fig. 5. Stress-strain curves for the alloy after HPT at $823 \mathrm{~K}$ and different strain rates.

relatively stable flow with a low stress value, occurs at the strain rate of $1.0 \times 10^{-4} \mathrm{~s}^{-1}$. When the strain rate increases, the stress increases markedly and extensive strain hardening appears in the primary deformation stage, especially when deformed at $5.0 \times 10^{-3} \mathrm{~s}^{-1}$.

The specimens prior to and after high temperature deformation are shown in Fig. 6. It is evident that the material exhibits good superplasticity when deformed at a relatively low temperature of $873 \mathrm{~K}$ within the strain rate range from $10^{-3}$ to $10^{-4} \mathrm{~s}^{-1}$. The specimen demonstrates a maximum elongation of $790 \%$ at $873 \mathrm{~K}$ and $10^{-4} \mathrm{~s}^{-1}$.

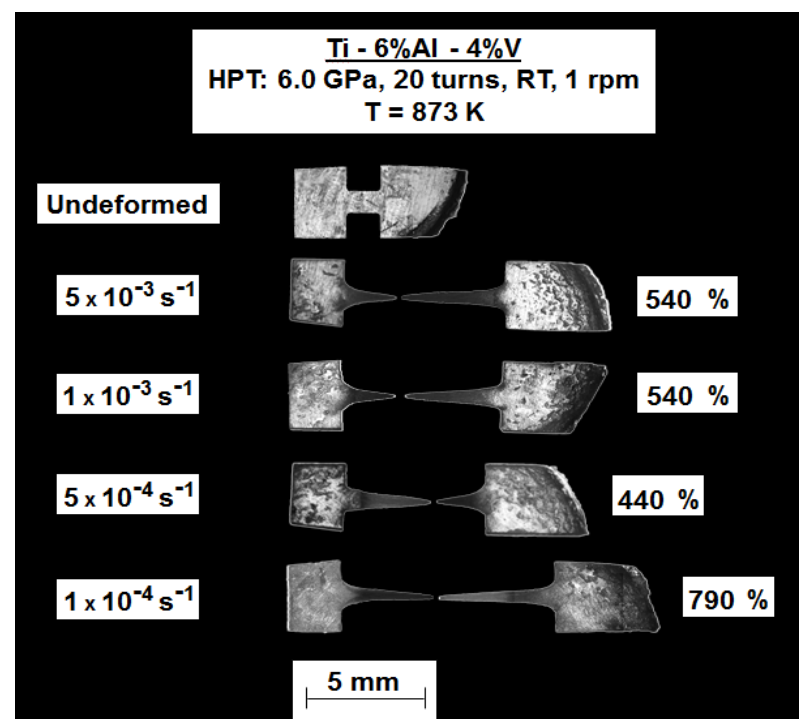

Fig. 6. Shapes of the Ti-6Al-4V specimens tested at $873 \mathrm{~K}$ after 20 turns of HPT processing.

\section{Discussion}

Generally, HPT processing can lead to an exceptional grain refinement of materials. In HPT processing, the factors in- 
fluencing grain size as well as the homogeneity of the microstructure are mainly the numbers of turns in torsion, the applied pressure, the frictional effects and temperature. For dual phase materials, the volume fractions of different phases and their morphology also affect the grain refining in HPT processing. The present work, together with previous studies [9-11], indicates that processing by HPT with some volume fractions of lamellar structure is more effective in producing an ultrafine grain structure in the alloys by comparison with the near phase materials in HPT processing for the Ti-6Al-4V alloy [2-5].

The influence of the phase volume fraction on grain refining of Ti-6Al-4V alloys by HPT has been investigated [10] and it was reported that higher hardness values and smaller grain sizes were attained in the alloy with approximately equal volume fractions of the constituent phases compared with the alloy containing $85 \%$ equiaxed $\alpha$ phase and $15 \%$ lamellar $(\alpha+\beta)$. In an earlier investigation [11], Ti-6Al-4V materials with three different phase volume fractions were chosen and the influence of the phase volume fraction on the grain refinement of the alloy was examined through processing by HPT. The results showed that the grain size decreased more obviously after HPT processing with increasing volume fraction of the lamellar structures.

In HPT processes, the deformation is mainly caused by the axial compression and shear deformation. As deformation proceeds, an interface stress between the $\alpha$ phase and $\beta$ phase is introduced due to the different features of the two phases such as deformation resistance in the Ti-6Al-4V alloys. For the lamellar structure, the stress concentration is more severe compared with the equiaxed grains in dual phase materials as it is more difficult to coordinate the deformation of two phase constituents. In HPT processing, there is dislocation slip accommodating the deformation strain and leading to dislocation tangles and cells. This interface stress increases with increasing strain which promotes dislocation movement and the formation of dislocation cells. From the present observations of the microstructural evolution, it is apparent there exists a transition from low-angle boundaries to highangle boundaries during the HPT processing. This process may be enhanced by the increase in dislocation density. Therefore, the grain refining effect is more obvious when increasing the volume fraction of the lamellar structure. Microstructural refinement by severe room temperature compression has been observed in a dual phase lamellar Ti-3Al-4.5V-5Mo alloy [15] and it was suggested that the interaction between the $\alpha$ phase and the $\beta$ phase also contributed to the microstructure refinement.

The superplastic deformation process is characterized as boundary sliding accommodated by dislocation slip and diffusion. For dual phase Ti-6Al-4V alloys, many studies have been carried out to clarify the effects of grain size and volume fraction of the two phase constituents on boundary sliding. A study was made to investigate boundary sliding and its accommodation mode with respect to the variation of grain size and the $\alpha / \beta$ fraction during superplastic deformation of a two-phase Ti-6Al-4V alloy [1]. It was reported that the sliding resistance for the different boundaries is lowest in the $\alpha / \beta$ phase boundary and increases in the order of $\alpha / \beta<<\alpha / \alpha \approx$ $\beta / \beta$ which plays an important role in controlling the super- plasticity of the alloys with various $\alpha / \beta$ phase ratios. It was also stated that the $\beta$ phase deforms more readily than the $\alpha$ phase at superplastic temperatures [5]. The $\beta$-phase usually favors superplasticity by promoting grain boundary sliding along the interphase boundaries and the appearance of even a small amount of $\beta$-phase in a Ti-6Al-4V alloy during heating would make a contribution to superplasticity by inhibiting significant growth and promoting grain boundary sliding.

Generally, superplastic flow in Ti-6Al-4V alloys is achieved at an intermediate temperature range which is higher than $1073 \mathrm{~K}$ [1] and most of the tensile tests of the materials processed by SPD have been conducted at temperatures equal to or higher than $923 \mathrm{~K}$ [2-5]. It is excellent to achieve superplasticity of the alloy in this investigation at the relatively low temperature of $873 \mathrm{~K}$. Thus, the material processed by HPT exhibits a very good superplasticity at a low temperature of $873 \mathrm{~K}$ and in the strain rate range of $10^{-3}-10^{-4} \mathrm{~s}^{-1}$.

In the present work, the volume fraction of the $\beta$ phase is significantly larger than in earlier reports [2-5] due to the difference in the microstructure prior to HPT. It was reported that the volume fraction of the $\beta$ phase in a Ti-6Al-4V alloy increases with increasing temperature and this is rapid beyond $1173 \mathrm{~K}$ but not markedly between 1023 and $1173 \mathrm{~K}$ [16]. Therefore, in the case of the low temperature superplasticity region of $873 \mathrm{~K}$ in the present work, the volume fraction of the $\beta$ phase present at the testing temperature is not significantly changed. Therefore, the initial volume fraction of the $\beta$ phase in the samples processed by HPT will exert an impact on the overall superplasticity. In the present investigation, the initial microstructure contains a large proportion of $\beta$ phase and it is anticipated that boundary sliding among the $\alpha / \beta$ interfaces contributes to the relatively high elongations of the material at this lower temperature. The present result suggests the potential for manipulating the volume fraction of lamellar structure and the interspacing of the lath and grain size of the a phase by adjusting the annealing schedules to further refine the grain size of the Ti-6Al-4V alloys during HPT and thus to achieve good superplasticity at an even lower temperature. This possibility will be investigated in future studies.

\section{Summary and conclusions}

1. A Ti-6Al-4V alloy was subjected to a heat treatment and the microstructure consisted of $\alpha$ phase and a lamellar $(\alpha+\beta)$ phase. The volume fractions were $25 \%$ a phase and 75 $\%$ lamellar $(\alpha+\beta)$ and the grain size of the $\alpha$ phase was $\sim 9.5$ $\mu \mathrm{m}$.

2. After 1 turn in HPT, traces of shear deformation appear. When the numbers of turns increase to 5 , shear deformation is more severe and the dislocation density increases. After 10 turns, the fibrous structure essentially has disappeared and ultrafine equiaxed grains are formed. When the deformation proceeds to 20 turns, high-angle boundaries are formed in the sample. The average size of the equiaxed grains was $77 \pm 15 \mathrm{~nm}$.

3. After HPT processing, the microhardness increased as the numbers of HPT turns increased. Initially, the distribution of microhardness along the radial direction was 
not homogeneous with low values in the center and higher values at the edge. The distribution of hardness tended to be relatively homogeneous when the HPT was continued to 20 turns.

4. The Ti-6Al-4V alloy demonstrates excellent superplasticity in the strain rate range of $10^{-3}-10^{-4} \mathrm{~s}^{-1}$ at $873 \mathrm{~K}$. A total elongation of $790 \%$ was achieved at $873 \mathrm{~K}$ and $1.0 \times 10^{-4} \mathrm{~s}^{-1}$ due to adequate phase boundary sliding.

Acknowledgements. This work was supported by the National Natural and Scientific Foundation of China (51334006), CAPES and the European Research Council under ERC Grant Agreement No. 267464-SPDMETALS.

\section{References}

1. J.S. Kim, Y.W. Chang, C.S. Lee, Metall. Mater. Trans. A 29A, 217 (1998).

2. Y.G. Ko, W.G. Kim, C.S. Lee, D.H. Shin, Mater. Sci. Eng. A 410-411, 156 (2005).

3. Y.G. Ko, C.S. Lee, D.H. Shin, S.L. Semiatin, Metall. Mater. Trans A 37A, 381 (2006).

4. A.V. Sergueeva, V.V. Stolyarov, R.Z. Valiev, A.K. Mukherjee, Scripta Mater. 43, 819 (2000).
5. A.V. Sergueeva, V.V. Stolyarov, R.Z. Valiev, A.K. Mukherjee, Mater. Sci. Eng. A 323, 318 (2002).

6. R.S. Misra, V.V. Stolyarov, C. Echer, R.Z. Valiev, A.K. Mukherjee, Mater. Sci. Eng. A 298, 44 (2001).

7. H. Matsumoto, K. Yoshida, S.H. Lee, Y. Ono, A Chiba, Mater. Lett. 98, 209 (2013).

8. H. Matsumoto, V. Velay, A. Chiba. Mater. Des. 66, 611 (2015).

9. Y.C. Wang, T.G. Langdon, Mater. Sci. Eng. A 559, 861 (2013).

10. Y.C. Wang, T.G. Langdon, J. Mater. Sci. 48, 4646 (2013).

11. J. Fu, H. Ding, Y. Huang, W.J. Zhang, T.G. Langdon, J. Mater. Res. Tech. 4 (1), 2 (2015).

12. A.P. Zhilyaev, T.G. Langdon, Prog. Mater. Sci. 53, 893 (2008).

13. R.B. Figueiredo, P.R. Cetlin, T.G. Langdon, Mater. Sci. Eng. A 528, 8198 (2011).

14. R.B. Figueiredo, P.H.R. Pereira, M.T.P. Aguilar, P.R. Cetlin, Acta Mater. 60, 3190 (2012).

15. Z.Q. Zhang L.M. Dong, Y. Yang, S.X. Guan, Y.Y. Liu, R. Yang, Trans. Nonferrous Met. Soc. China 22, 2604 (2012).

16. T. Seshacharyulu, S.C. Medeiros, W.G. Frazier, Y.V.R.K. Prasad, Mater. Sci. Eng. A 284, 184 (2000). 